\title{
FRANCISCO DE VITORIA: LA SOCIEDAD INTERNACIONAL, UN IDEAL REALIZABLE
}

\author{
M.. Lourdes Redondo Redondo \\ I.E.S. «Luis de Rosales» (Móstoles, Madrid)
}

\begin{abstract}
RESUMEN
La idea vitoriana de Sociedad Internacional no es una utopía irrealizable. En su metodología apreciamos la armonía experiencia/razón y razón/fe que bebe de santo Tomás. Parte de un examen pormenorizado de los hechos de la realidad indiana y de principios universales, metafísicos y teológicos, sobre el hombre y la moral; lo cual le permite razonar inductiva-deductivamente con prudencia y con realismo.
\end{abstract}

Palabras clave: Vitoria (Francisco), Sociedad internacional, Indias

\begin{abstract}
Victoria's idea of International Society is not an unfeasible Utopia. The harmony between experience/reason and reason/faith which he imbibes from St. Thomas Aquinas can be appreciated in his methodology. His anthropology is also realistic, that is to say, objectivistic: human nature is the same in all men; their dignity and rights as persons are not given or taken by their faith. Vitoria applies to the Indians the Tomist thesis on the person and the relationship faith/reason, nature/over nature.
\end{abstract}

Keywords: Vitoria (Francis), International Society, Indies

\section{EL REALISMO DE FRANCISCO DE VITORIA}

La definición de «sociedad» como «conjunto de personas cuya unidad se debe a un fin común» puede parecer utópica si entendemos la palabra «unidad» en su verdadero sentido, como resultado de la armonía, unidad que integra las diferencias frente a la uniformidad masificadora. Así, pues, sociedad no es ni divisionismo particularista ni igualitarismo totalitario. En una sociedad hay armonía, libertad dentro de un orden.

Esto que podemos entender como posible en pequeñas sociedades ¿lo es a escala internacional? ¿Es posible armonizar diferentes culturas, religiones, economías, políticas...? ¿Qué fin común es el capaz de llevar acabo esta unidad?

Nuestra larga historia y la actual realidad mundial nos inclinan a pensar que es una utopía. La cuestión es esta ¿es irrealizable en sí mismo este ideal de modo que intentarlo podría llevarnos a desastres a los que han llevado las utopías políticas? Intento demostrar en este breve trabajo que no es irrealizable. $Y$ no lo es porque se apoya en un profundo realismo, el realismo de la naturaleza humana, esencialmente social.

Francisco de Vitoria, apoyándose en santo Tomás — profundamente realista--, pone las bases para que esta Sociedad Internacional que él idea, sea posible. Este trabajo consiste en analizar estas bases - metodológicas y antropológicas-, lo que nos permitirá demostrar que se trata de un ideal realizable. Añadiremos también hechos que demuestran que, además, se ha realizado en parte, y las causas que explican por qué no se ha realizado del todo. 
Antonio Truyol Serra, refiriéndose a la actitud de Vitoria ante el imperativo de su siglo que pedía soluciones a nuevos problemas planteados por el descubrimiento del Nuevo Mundo y a la vez por el individualismo político de los estados modernos, escribe: «Encontramos en ella (en esta actitud) aquel exquisito sentido de la medida, de la continuidad histórica, del equilibrio intelectual y moral que huye, por igual, de la utopía irrealizable y de la claudicación ante lo fáctico». ${ }^{1}$

Es por su sentido de la armonía, como veremos, por lo que su solución es realista y realizable, mucho más de lo que sería una solución meramente positivista y fáctica, por lo mismo incapaz de ser solución duradera. Su realismo y equilibrio constituyen la base metodológica fundamental: la armonía experiencia / razón, fe y razón.

Es realista por su actitud de apertura y respeto a la verdad, cualquiera que sea, la fáctica y la del «deber ser». Parte de la experiencia e ilumina esa experiencia con la inteligencia que descubre en ella la naturaleza y la esencia de las cosas, inteligencia que permite abrirse a la fe, descubridora de nuevas y más profundas realidades.

\section{BASES METODOLÓGICAS: ARMONÍA EXPERIENCIA, RAZÓN, RAZÓN / FE}

a) Experiencia iluminada por la razón. Atenencia a los hechos y a la naturaleza humana

Su pensamiento se ha elaborado partiendo de la realidad histórica y metafísica del hombre, su naturaleza, idéntica siempre, pero en dinamismo. Con método inductivo y deductivo, se atiene a los hechos y a los principios rectores. Pero, parte de los hechos.

b) Atenencia a los hechos

Dice Brown Scott ${ }^{2}$ que Vitoria es innovador porque inicia una filosofía que desciende al caso concreto. Afirma que es menester un conocimiento exhaustivo de los hechos y una adecuada deliberación antes de decidir sobre la justicia o injusticia de determinadas leyes o conductas (Introducción a De Indis). Porque leyes justas en teoría pueden resultar injustas al aplicarlas por no estar la realidad preparada. En ello seguía a santo Tomás, quien, citando a su vez, a san Isidoro, decía que la ley, para ser justa, debe ser posible. Sin experiencia no hay prudencia ni buen gobierno. «Las reglas morales no deben ocuparse de meras posibilidades, sino de cosas que realmente ocurren», dice en las Lecciones de 1534 comentando a santo Tomás en la q. 10 a. 8 de la II-II.

Vitoria pone en práctica estos principios realistas. Antes de escribir examina los hechos. Me voy a referir al problema indiano, analizando brevemente el conocimiento que tiene de esa realidad. Se vale de diversas fuentes.

Las crónicas y relatos de testigos. Son los testimonios oficiales de soldados o conquistadores que pretenden justificarse echando las culpas a los indios; o relatos de éstos o personas afines, también tendenciosos en sentido contrario, por lo general. Estas fuentes suelen ser contradictorias. Más objetiva es la crónica de Cristóbal Mena: La conquista del Perú llamado de la Nueva Castilla (Sevilla, 1534), una de las fuentes más importantes de Vitoria, a juzgar por su coincidencia crítica.

Están también las fuentes orales, pues había muchos «peruleros» - los que venían de Perúen Salamanca y consta que era solicitado por ellos para resolver dudas de conciencia, como él mismo escribe en su carta al P. Arcos (1534). Hay, pues, crónicas, testimonios de soldados e indígenas, memoriales de agravios y reivindicaciones, etc. Vitoria se enfrenta a una maraña de fuentes y adopta ante ellas una postura equilibrada, ausente de prejuicios positivos o negativos.

1 Truyol Serra, A: Los principios de Derecho Público en Francisco de Vitoria. Selección de textos con introducción y notas de A. Truyol Serra. Madrid, Eds. Cultura Hispánica, 1946.

2 Brown Scott, El origen español del Derecho Internacional Valladolid, 1928, p. 64. 
Tiene, además, como fuente, las disposiciones jurídicas que, sin duda, conocería (las Leyes de Burgos, sobre todo) y los testimonios de misioneros, sobre todo dominicos, que, en gran parte, salían del convento de San Esteban de Salamanca. ${ }^{3}$ De allí era el célebre dominico Montesinos, cuyo famoso sermón, aprobado por el resto de los dominicos que estaban con él en La Española, suponía previas reflexiones sobre el tema y, sobre todo, un espíritu en el que habían sido educados, el mismo en el que se educaría Vitoria. Según Chacón y Calvo «hay una unidad ética entre el sermón de Montesinos y la Relección De Indis». ${ }^{4}$ La tradición humanitaria y teológica sobre la hominidad y libertad de los indios que había en Salamanca permite entender las Relecciones. ${ }^{5}$

Hay, además, testimonios de misioneros no dominicos e incluso seglares que pudieron influir en Vitoria (Vasco de Quiroga, Julián Garcés, Juan de Zumárraga, etc.).

En resumen, Vitoria parte de un conocimiento exhaustivo de la realidad, que es lo que le impulsa a intervenir en el problema indiano. Tiene, pues, un punto de partida realista para elaborar una teoría que cambiará el rumbo de las ideas y la legislación.

El papel de la experiencia en el método de Vitoria es la clave para entender su postura moderada, equilibrada, realista. Método y conclusiones son lo suficientemente flexibles para acomodarse a la variada realidad y para modificarla. Es la experiencia la que le da esa flexibilidad. Hay afirmaciones categóricas, pero también muchas probables y relativas a las circunstancias.

El campo jurídico se mueve con frecuencia en este terreno, apelando para establecer las leyes, a la costumbre, a la mayor probabilidad, al mal menor, a las circunstancias, las opiniones de expertos, la certeza subjetiva... Pero, no sólo a eso, porque entonces el Derecho se apoyaría sólo en lo relativo, con lo cual quedaría sin apoyo. Es preciso tener principios absolutos, claros. Vitoria conjuga ambas fuentes: experiencia y razón. La seguridad con que se mantienen los primeros principios se va matizando a medida que se desciende al caso concreto. De este modo, incorpora el discurso histórico a los argumentos deductivos y, según dice Osuna Fernández-Largo: "Vitoria inició una nueva andadura». ${ }^{6}$

Confirmando la importancia del método histórico en Vitoria, dice Brown Scott que sus alusiones a sucesos contemporáneos son relativamente más frecuentes que en Gentile, que tiene fama de ello. Una de las innovaciones de Vitoria está en haber dejado los viejos métodos escolásticos consistentes en tratar problemas teóricos y abstractos y haber sabido exponer los derechos y los deberes de los indios y de España.

3 Dice Baumel: «Ahora se encontraba Vitoria en el convento de San Esteban de Salamanca; en tal ambiente participaba de todas las discusiones, todas las ansiedades y todas las esperanzas. Él elaboraba progresivamente su obra sobre la colonización con los datos de la realidad». Les problèmes de la colonisation et de la guèrre dans l'oeuvre de F.de V. Montpellier, 1936, p. 120

4 Cedulario cubano. Introducción. (Colección de Documentos Inéditos para la Historia de Hispanoamérica vol. 1, p. XXXV. Entre los muchos testimonios de dominicos a favor de los indios que se conservan, destaca el de F. Bernardino de Minaya, también educado en Salamanca. Fue el que obtuvo de Paulo IlI el reconocimiento de la hominidad de los indios con los Breves Pastorale Oficcium y Sublimis Deus (1537). Se había levantado una gran polémica en torno a este asunto y Minaya quiso venir personalmente a España a entrevistarse con el rey y más tarde a Roma, con el Papa, el cual respondió con los mencionados decretos.

5 Estas nacieron con los problemas prácticos que desde 1512 se plantearon en consejos y confesionarios de Valladolid y Salamanca y de las frecuentes conversaciones de misioneros que iban y venían de las misiones, que fueron incontables. Cf. Cuervo: Historiadores del convento de San Esteban de Salamanca. Salamanca, 1914. «El catedrático de Prima (Vitoria) — nos dice Teófilo Urdánoz — no podía permanecer ausente de aquel bullir de preocupaciones y realidades nuevas. Por fuerza debían plantearse en las aulas los nuevos problemas que suscitaban las guerras de conquista, el sistema de encomiendas y repartimientos, la tiranía y esclavitud de los indios, y con frecuencia serían objeto de reflexiones».

6 Osuna Fernández-Largo, A.: «De la idea del Sacro Imperio al Derecho Internacional». En La ciencia Tomista. Tomo 111, 1984 
La armonía entre ideas y hechos explica la armonía entre teología, moral y derecho. Como moralista y teólogo debe elevarse a los principios, pero como jurista debe concretar. Escribe García Villoslada que Vitoria se distingue por el «cultivo de la teología práctica (moral y derecho) pero con carácter universalista y humano que, sin perder el contacto con la realidad de los hechos plantea y resuelve los problemas no con arreglo a cánones de valor circunstancial, no menos a dictámenes arbitrarios de decretista, sino en conformidad y derivación de los principios eternos e inmutables de la razón y del dogma (...) No desdeña la especulación, pero se remonta a ella partiendo de los hechos concretos, históricos, no construyendo teorías a priori». ${ }^{7}$

\section{c) Atenencia a la naturaleza humana}

Es realista también Vitoria, como Sto. Tomás, por su atenencia a la naturaleza humana. Pero de ello hablaré a continuación, en el punto 3. Paso a hablar brevemente de otra base metodológica que sostiene todo el sistema.

\section{d) La armonía fe/razón, natural/sobrenatural}

Frente a teorías teocráticas que absorben lo natural en lo sobrenatural, la razón en la fe; o frente a las teorías nominalistas que disgregan ambos campos, Santo Tomás, y aquí cabe cifrar su principal aportación, por radical, sostiene la armonía entre ambos campos. Distinción pero complementación. Esto será fundamental en la historia y en el caso concreto de la solución vitoriana al hecho americano.

Principio básico tomista: Gratia non destruit naturam sed perficit: Ius divinum quod est ex gratia non destruit ius humanum quod est ex naturale ratione. ${ }^{8}$ En la I ${ }^{\mathrm{a}} \mathrm{q} .98$ a. 2 , dice: Ea enim quae sunt naturalia neque dantur neque substrahuntur homini per peccatum.

Para conocer la dignidad del hombre como tal, por tanto, no es necesario elevarse al plano sobrenatural y de la fe. Basta con la sola razón, porque tal dignidad radica en la naturaleza, y sólo atendiendo a ella podrán establecerse los derechos de los hombres y de los pueblos, cristianos o no. Es verdad que la dimensión sobrenatural eleva esta dignidad a un grado infinito, y que la vida del hombre y de la sociedad deben ordenarse hacia su perfección, que es la salvación, pero esto no significa que la sociedad civil tenga este fin como específico suyo; éste es el fin de la Iglesia. La sociedad civil debe atender a un fin natural y secular; ahora bien, no debe obstaculizar el fin sobrenatural, sino, más bien, ayudar a conseguirlo. Caso contrario, sería legítima la intervención de la Iglesia para defenderse, como sociedad perfecta que es, e independiente. Al igual que el estado, también sociedad perfecta, puede legítimamente defenderse si es atacado.

Esta base metodológica permite defender los derechos naturales de los hombres y de los pueblos, pasar del concepto de «Cristiandad» al de «Sociedad internacional». ${ }^{9}$

7 García Villoslada, R.: La universidad de París durante los estudios de $F$, de $V$. Universitas Gregoriana.Roma, 1938, p. 10. Antes de Vitoria los teólogos o canonistas escribían en sus celdas disposiciones de la ley en abstracto, y tocaba a los estadistas o a los soldados establecer la ley en concreto. La originalidad de Vitoria está en ser el primero en hacer teología aplicada, es el propio teólogo el que la debe hacer. Cf. Brwon Scott, El origen español del Derecho Internacional, p. 64.

8 S. Th. II-II, q. 10, a. 10.

9 Otra cosa es que la «Cristiandad», la unión de todos los hombres por una misma fe, no sea el ideal. Este ideal era, sin duda, el de Sto. Tomás y el de Vitoria, pero es un ideal y, entonces y ahora, a él habrá que llegar por la vía del realismo. En tanto los hombres no tengan una misma fe, la convivencia tendrá que organizarse del modo más justo y solidario posible, respetando los derechos naturales y no imponiendo la fe por la fuerza. La teoría teocrática pecaba de idealismo. 


\section{BASES ANTROPOLÓGICAS}

\section{a) Naturaleza social y singular del hombre}

La sociabilidad, exigida por su naturaleza racional y libre, es presupuesto de su teoría internacionalista. Se trata de una sociabilidad multiforme y dinámica que no se agota en la familia o estado, como pretendía Aristóteles, sino que abarca al género humano.

Esta sociabilidad funda la importancia del bien común como fin que debe procurar la sociedad y éste exige la autoridad. Escribe Vitoria en De potestate civili: «... ninguna sociedad puede persistir sin alguna fuerza o potestad que gobierne y provea. La misma es, pues, la utilidad y el uso del poder público que el de la comunidad y la sociedad». ${ }^{10}$

El hombre, por otra parte, es un ser singular, subsistente. En la subsistencia, que es ser «por sí mismo», consiste el ser persona, según Sto. Tomás (I, q. 29). Por ello, la persona es sujeto de sus acciones, de las cuales es responsable. El fondo íntimo del ser del hombre, donde radica su libertad, es esa subsistencia, que es incomunicable y le da esa singularidad característica, su «yo» insustituible. A la vez le da ese dominio de sí («sui iuris»). En ello radica su dignidad, base de todos los demás derechos. Dignidad significa lo mismo que persona: «lo más perfecto de toda la realidad». Así define a la persona santo Tomás (I, q. 29, a.3). Por ello, en grado absoluto, corresponde a Dios este término de «persona» ( «Ipsum esse subsistens») y, en grado participado, según la naturaleza racional, al hombre. De esta subsistencia se sigue su obrar consciente, libre, responsable, con autoridad y dominio sobre los propios actos o los ajenos. La singularidad, libertad y dominio van unidos. ${ }^{11} \mathrm{El}$ hombre no pertenece a otro, como Aristoteles consideraba al esclavo (Política, I, 2).

Esta singularidad no se opone a la sociabilidad. El hombre insolidario no lo es por ser singular y tener conciencia de su intimidad insustituible; no lo es por ser libre, sino por hacer un uso indebido de su libertad. La singularidad se armoniza con la solidaridad, lo mismo que con la igualdad. Todos los hombres son iguales en dignidad, es decir, en cuanto que cada uno de ellos es persona, singular e insustituible. La sociedad sólo es posible en esta armonía de identidad y diferencia.

Del ser personal (que tienen todos y cada uno de los hombres) derivan su dignidad y sus derechos. Paso a examinarlos a la luz del término empleado por santo Tomás y Vitoria: «dominio», mostrando la armonía entre los derechos del hombre y de la sociedad.

b) Derechos del hombre y de la sociedad. El dominio y su universalidad

¿En qué consiste el dominio? Universalidad del mismo. Dominio es lo mismo que derecho, viene a decir Vitoria, comentando la q. 62 de la II-II de Sto. Tomás, donde nos habla de la obligación de restituir, a propósito de la virtud de la justicia: «En sentido general, es la facultad de usar algo según el derecho». De este modo, sigue diciendo Vitoria: Idem erit ius et dominium. ${ }^{12}$ Los derechos humanos son todo aquello que le pertenece en justicia al hombre o de lo que tiene dominio

10 Edición de Urdánoz, p. 157.

11 Dice santo Tomás: «Pero de manera más especial y perfecta se halla lo particular e individual en las substancias racionales, que son dueñas de sus actos y no se limitan a obrar impulsadas, como sucede a las otras, sino que se impulsan a sí mismas, y las acciones están en los singulares. Por este motivo, los singulares de naturaleza racional tienen, entre todas las demás substancias, un nombre especial, que es el de personan (I q. 29 a. 1, Resp.).

12 Las citas de los comentarios de Vitoria a la II II de Sto. Tomás están tomados de la edición preparada por Beltrán de Heredia, Salamanca, 1932-35, 5 vols. Nos centraremos en los volúmenes 3 y 4 que tratan de la virtud de la justicia. Sólo aparecen citas del volumen 3, que citaremos de la siguiente manera: «De Iustitia, I», seguido del número de la página. Las citas traducidas lo han sido por mí. 
No se trata, pues, del dominio entendido como «poder», sino «aquello que es lícito por leyes». Este derecho o dominio es el que corresponde al hombre, que lo ha recibido de Dios. Sólo Dios, en sentido estricto, es dueño, por ser plenamente «sui iuris». «Por gracia nos ha concedido el uso de las cosas, no porque fuésemos dueños», dice Vitoria (De Iustitia, I, 69). Luego puede usarlas, tiene derecho a hacerlo, es justo. Este derecho que el hombre tiene (y no los animales, a no ser en sentido abusivo) es un derecho divino natural, y es «per se notum», según Vitoria, que lo tienen todos los hombres (De Iustitia, I, 72), y es sólo en usufructo, al servicio del bien común. Existe una deuda que saldar con él, un deber.

Este dominio - - estos derechos humanos--, es universal. Lo tienen todos los hombres por naturaleza y no puede ser abolido por motivo sobrenatural (pecado mortal o infidelidad), como dice santo Tomás (II-II q. 10 a. 12), en quien se apoya Vitoria para defender el dominio de los indios: «La infidelidad no destruye el derecho natural ni el humano positivo...». ${ }^{13}$ Tampoco se requiere para ser capaz de dominio tener uso de razón. Tanto un niño como un amente son dueños porque la capacidad racional no es necesario que esté actualizada, dice Vitoria. «Y, en fin, no es lo mismo que la criatura irracional; porque no es el niño para utilidad de otro, como lo son los brutos, sino un ser de personalidad propia e inalienable». ${ }^{14}$

c) Clases de dominio

El hombre tiene dominio o derecho sobre sí mismo, sobre las cosas (propiedad) y sobre los demás (autoridad):

1. Sobre sí mismo. Dentro de este campo vamos a hablar del derecho a la libertad de conciencia y del derecho a la vida e integridad física.

Derecho a la libertad de conciencia. El hombre es «sui iuris», «dueño de sus actos» (I-П q. 1 a. 1). Vitoria, apoyándose en textos de santo Tomás, ${ }^{15}$ dice que todos los hombres tienen dominio, primero, sobre sí, "porque los hombres no han nacido siervos, sino libres», «por derecho natural». ${ }^{16}$ De ello se deduce la libertad de conciencia, tal y como santo Tomás defendía: «Credere voluntatis est ( $\Pi-\Pi$ q. 10 a. 8). Por eso, nadie puede ser forzado a creer. El hombre (el indio, consiguientemente) es dueño de su conciencia, que es terreno inviolable. Ni siquiera el príncipe del que es súbdito tiene dominio sobre él, cuanto menos un príncipe extranjero.

Vitoria se detiene en este tema, entrando en la polémica secular de si se debe o no obligar a los infieles a convertirse ${ }^{17}$. Delibera mucho y concluye que ni el Emperador ni el Papa pueden obligar a los indios a convertirse por la fuerza pues no son súbditos suyos. Los indios tienen libertad de conciencia. De ahí la ilegitimidad de los títulos de conquista $4^{\circ}$ (no aceptar la fe) y $5^{\circ}$ (pecados contra la naturaleza). ${ }^{18}$

Pero esto no quita la obligación de educar y evangelizar. El ser independiente no se opone al derecho a ser educado. De ahí que Vitoria encabece la relección De Indis con este tex to bíblico: «Id y enseñad a todas las gentes, bautizándolas ...» (Mt 28, 19), texto que constituye el tema de la «relección».

\footnotetext{
13 De Indis. Ed. de Urdánoz, p. 656.

14 Ibid., p. 664.

15 Comentarios a la II-II, q. 63 a. 1 (De Iustitia, I, 228).

16 Ibid., p. 670.

17 A ello dedica el $2^{\circ}$ y el $4^{\circ}$ título ilegítimos y el $2^{2}, 3^{\circ}$ y $4^{\circ}$ legítimos, el fragmento de la relección $D e$ temperantia (Urdánoz, 1039-1059), y el a. 8 de la q. 10 de los Comentarios a la II-II de Sto. Tomás (Lecciones de 1534) (en Relectio De Indis, Ed, del C.S.I.C., Madrid, 1967. Colección Corpus Hispanorum de Pace, dirigida por Luciano Pereña, tomo V. En adelante citaremos esta edición por «C.H.P., 5» y la que corresponda a la relección De Iure Belli por «C.H.P., 6» por estar editada en la misma colección, tomo VI.

18 De Indis. Parecer de los teólogos de Salamanca sobre el bautismo de los indios, C.H.P., 5, 158, In II-II, q. 10 a. 8, C.H.P., 5, 116-137. Cf. mi libro Utopia vitoriana y realidad indiana, Fundación Universitaria Española, Madrid, 1992, pp.148 ss.
} 
Vitoria defiende la evangelización pacífica y el respeto a las costumbres indígenas, siempre y cuando no vayan en contra del bien común. Es exigencia evangélica y de la naturaleza humana, que manda ser solidarios con todos los hombres. Los títulos legítimos de conquista: $2^{\circ}$ (Derecho a la propagación de la fe), $3^{\circ}$ (Por impedir que los convertidos practiquen), $4^{\circ}$ (Dar un príncipe cristiano a los convertidos) y $8^{\circ}$ (Protectorado especial), se refieren a esto. Se trata, el de la evangelización y educación, de un derecho-deber de españoles que conlleva el respectivo derecho-deber en los indios de permitirlo. Si es impedido, se justifica la intervención española en Indias. ${ }^{19}$ Los medios que propone Vitoria son: Predicación y buenos ejemplos, ${ }^{20}$ conquista y coacción si no hay más remedio, y, sobre todo, en defensa de alguna injuria recibida o para defender a los inocentes — en todo caso, debe hacerse con moderación — ${ }^{21}$ y Protectorado español, que supone un fomento de la cultura, educación y progreso material. ${ }^{22}$

Todo esto que, según Vitoria, exige la sociabilidad natural, debe compaginarse con el respeto a la singularidad. Es ésta una de las bases en que se asienta la prueba de la ilegitimidad de los falsos títulos: los indios tienen su propia religión, cultura, costumbres, príncipes, magistrados..., que deben ser respetados, siempre y cuando no atenten contra los derechos de otros. Así, pues, la sociabilidad justifica los títulos legítimos, y la singularidad prueba los falsos títulos.

\section{Derecho a la vida e integridad física y moral}

En los Comentarios a la q. 64 de la II-II de santo Tomás (sobre la virtud de la justicia), en el a. 6 se pregunta si es lícito, en algún caso, matar a un inocente. Responde: «Ad hoc absolute respondeo quod nullo modo licet innocentem occidere, nec invitum nec volentem».

De ningún modo, pues, se puede matar y torturar a los indios inocentes; pero, del mismo modo, existe la obligación de acudir en defensa de los inocentes atacados o torturados. Es esta defensa del inocente, en virtud del derecho a la vida la que podría hacer lícita la intervención española en Indias cuando se tratara de defender inocentes oprimidos por leyes injustas $\left(5^{\circ}\right.$ título legítimo), ${ }^{23}$ así lo establecen las condiciones de la guerra justa que santo Tomás defiende en la q. 40 de la II- II (llamada De bello) que Vitoria comenta y a cuyo tema dedica una relección: De iure belli.

\section{Dominio sobre las cosas (propiedad)}

Vitoria, apoyándose también en Sto. Tomás (Comentarios a la q. 66 de la II-II), defiende que todos los hombre tienen derecho a la propiedad. Ésta, dice, era originalmente común a todos los hombres pero se procedió a la división de la propiedad por derecho de gentes, que, lejos de oponerse al derecho natural, al hacerlo, vino a hacerlo efectivo en la práctica, pues el hombre, precisamente porque era dueño de las cosas, vio más conveniente dividirlas. (Cf. In $\Pi-\Pi$, q. 62). No es, por tanto, la propiedad privada una revocación del derecho natural hecha a raíz del pecado original, como decía Escoto, sino que, por el contrario, es una manera de hacerlo efectivo.

19 L. Redondo, Utopía vitoriana, o. c., p. 148.

20 Cf. Parecer de los teólogos de Salamanca sobre el Bautismo de los indios, C.H.P., 5, 158).

21 Cf. De Indis, Urdánoz, 717 ss.; De Iustitia, (C.H.P., 5, 141); De temperantia, (C.H.P., 5, 103 ss.).

$228^{\circ}$ título legítimo. De indis, Urdánoz, 723 ss.

23 De hecho ocurría que los indios, por lo general, tenían costumbres bárbaras, como hacer sacrificios humanos a los dioses, antropofagia y regímenes de gobierno tiránico que oprimían a la población. Vitoria consideraba un deber de solidaridad acudir en su ayuda, para lo cual se justificaba la violencia si era el único modo de restablecer la justicia. Dice en la relección De temperantia: «Los príncipes cristianos pueden hacer la guerra a los bárbaros porque se alimentan de carne humana y sacrifican hombres». El motivo es que «infieren injurias a los hombres» (C.H.P., 5, 110). Y en el 5º título legítimo afirma que los indios deben ser defendidos, aunque no quieran: «pues no son en esto dueños de sí mismos, ni tienen derecho a entregarse a sí y a sus hijos a la muerte» ( $D e$ indis, Urdánoz, 720, 721). 
Pero importa señalar, junto al derecho a la propiedad privada, la función social de ésta. El derecho a la propiedad ha de subordinarse al bien común. Es lícito y necesario que el hombre posea las cosas como propias, pues es la mejor manera de administrarlas, pero en cuanto al uso o disfrute, el hombre no debe tenerlas como propias, sino como comunes, «de modo que fácilmente dé participación con ellas a los otros cuando lo necesiten». En este sentido, coincide con S. Ambrosio cuando dice: «Nadie llame propio a lo que es común», y añade: «Lo que excede de lo necesario para el gasto, se ha obtenido violentamente» (II- II q. 62 a. 2).

En definitiva, respecto al derecho a la propiedad, sienta Vitoria estos principios:

- La propiedad privada: Si algo se le arrebata a su legítimo propietario se incurre en hurto y hay obligación de restituir.

- Derecho de invención y descubrimiento de aquellas cosas que son "res nullius».

- «Ius societatis et communicationis». Consiste en el derecho a usar de aquellas tierras que son comunes, siempre y cuando no vaya en perjuicio de sus posesores. ${ }^{24}$

Vitoria aplica estos principios a la realidad indiana:

- Los indios son legítimos propietarios. Por tanto, no es lícito hacer la guerra para apoderarse de sus bienes, pues sus territorios no son «res nullius» ${ }^{25} \mathrm{y}$, supuesta la justicia de la guerra, no es lícito aprovecharse más de lo justo. Se debe evitar el saqueo para el lucro. ${ }^{26}$ Por otra parte, el rey está obligado a defender sus bienes y a fomentarlos, ${ }^{27}$ a poner buenos ministros que hagan cumplir las leyes y a poner tributos justos, iguales que al resto de losúbditos cristianos.

Quizá el mérito innovador de Vitoria radica en el «ius societatis et communicationis» (Primer título legítimo), fundado en el carácter natural de la propiedad común y en la naturaleza social del hombre. Es un derecho fecundísimo en contenido que explicitará enumerando los derechos que surgen de él, tanto referidos a los individuos como a las naciones. Darán lugar a los derechos de extranjería recogidos en el derecho internacional privado y público. Las reglas jurídicas que emanarán de ellos obligan a los Estados entre sí a que traten de manera justa a los individuos, en cuanto personas y en cuanto miembros de una nación. Vitoria insiste en que se trata de derechos naturales de la humanidad antes de la división de las nacionalidades. Entre estos derechos distingue la libertad de tránsito, de comercio, de uso de los bienes comunes a los extranjeros, de residencia, nacionalización y ciudadanía. Si se les niega estos derechos a los extranjeros, pueden defenderse, incluso por la fuerza, pero siempre con la debida moderación.

Estos derechos que Vitoria enuncia en el primer título legítimo no son absolutos, sino relativos. Están limitados por los derechos de la nación propietaria a no ser perjudicada en sus bienes. Por ello, son susceptibles de modificación.

4. Dominio sobre los hombres (autoridad)

Este dominio funda el poder político que se entiende como servicio. Por eso no va contra los anteriores dominios sino que ha de servir para protegerlos. No se extiende este poder, por otra parte, a la esfera personal y moral del hombre, sino a sus actos externos, en cuanto que el hombre es miembro de una sociedad que ha de dirigirse al bien común.

24 Cf. De Indis, Título 1ํogítimo, Ed. de Urdánoz, 705, ss.

25 «Queda, pues, firme de todo lo dicho, que los bárbaros eran, sin duda alguna, verdaderos dueños, pública y privadamente, de igual modo que los cristianos (...) y grave cosa sería negarles a éstos, que nunca nos hicieron la más leve injuria, lo que no negamos a los sarracenos y judíos, perpetuos enemigos de la religión cristiana, a quienes concedemos el tener verdadero dominio de sus cosas si, por otra parte, no han ocupado las tierras de cristianos» (De indis, Urdánoz, 665).

26 De Iustitia, I, 342-344; De Iure Belli, Quaestio De bello, C.H.P., 6, 123, 132, 149, 195, 235-237; De Temperantia, C.H.P., $5,114,115$.

27 No debe permitir que sean expoliados de su riqueza y oro en beneficio de otra república: «Si el rey permitiese que el oro saliese de España hacia Italia, obraría mal. Luego lo mismo sucede con ellos, supuesta que no hay causa razonable para ello» (De temperantia, C.H.P., 5, 112 y 113 ) 
Vitoria (De potestate civili) afirma con claridad la legitimidad del poder político de los infieles, pues éste, como vimos, no se pierde por la infidelidad. ${ }^{28} \mathrm{Y}$ este dominio lo mantienen, incluso, entre los cristianos. ${ }^{29}$ No existe un poder universal por naturaleza. Pues, si bien el poder tiene su origen en la naturaleza, la potestad concreta es de derecho humano constituida por la ley. ${ }^{30}$ Por tanto, el emperador no es señor del mundo, ni Dios otorgó el imperio a nadie en particular ni el Papa es señor del mundo pues su poder no se refiere a lo temporal sino a lo espiritual y sólo se extiende a los bautizados. Ahora bien, respecto a las relaciones entre el poder espiritual y temporal hay que decir que, si bien sus fines son distintos, deben buscar en último término la perfección del hombre o la santidad. Por ello, el poder temporal no debe obstaculizar el espiritual. Caso de hacerlo, la Iglesia tendría derecho a defenderse, incluso por la fuerza, como cualquier estado ofendido. Todo ello se desprende de lo dicho en el punto 2.2 acerca de la armonía entre fe/razón.

Los pueblos indios, como naciones que son, son repúblicas perfectas, independientes, por tanto, de otras sociedades, aunque sean la Iglesia y el Imperio. Esta independencia les permite organizarse según sus propias leyes y defenderse de otros si les atacan, en cuyo caso, la guerra sería justa. ${ }^{31}$ Su príncipe no debe permitir que sean expoliados de sus bienes en beneficio de otra nación y, si son regidos por un príncipe extranjero, éste debe obrar con ellos como con su propia nación. ${ }^{32}$

En conclusión, los pueblos indios tienen soberanía e independencia política, no deben explotarse en beneficio de otros, tienen autoridad legítima y tienen derecho a defenderse contra las agresiones de otros pueblos. En ese caso, la guerra sería justa. ${ }^{33}$

\section{LA SOCIEDAD INTERNACIONAL}

Ha sido gran mérito de Vitoria el señalar el aspecto internacional del Derecho de gentes. La idea universalista del derecho no era nueva. Ya entre los romanos el «ius gentium» comprendía los derechos de todos los hombres; por eso se aplicaba a los extranjeros, pues en cuanto hombres, tenían los mismos derechos que los ciudadanos romanos. Estos derechos de «extranjería» que pertenecen al Derecho Internacional Privado, van a ser muy estudiados por Vitoria a propósito del «ius societatis et communicationis». Pero más allá está el Derecho Internacional propiamente tal o el Derecho Internacional Público que regula las relaciones entre las naciones. Es Vitoria quien establece este Derecho. Alois Dempf, que concede a Vitoria el carácter de fundador del Derecho Internacional, afirma que, no obstante, su principal valor radica, más que en ello, en haber aplicado universalmente el derecho natural a todos los hombres, en concreto, a los indios. ${ }^{34}$ Cierto, pero esto no disminuye la importancia de regular las relaciones entre los estados, sin lo cual no se podrían custodiar los derechos de los hombres, miembros de tales estados.

28 «No se puede poner en duda que entre los paganos haya legítimos príncipes (...) Ni siquierea los príncipes cristianos seculares o eclesiásticos pueden privar de ese poder a los príncipes infieles por el solo título de ser infieles, si no han recibido de ellos ninguna otra injuria» (De potestate civili, Urdánoz, 165).

29 In II-II, q. 10 a. 8, C.H.P., 5, 132.

30 Ibid, q. 10 a. 10.

31 Cf. De iure belli, C.H.P., 6, 117.

32 Sería, éste, el caso de que los indios fuesen gobernados por el rey de España, en forma de protectorado, como defendía Vitoria: «Podría, entonces, decirse que para utilidad de ellos pueden los reyes de España tomar a su cargo la administración de aquellos bárbaros, nombrar prefectos y gobernadores para sus ciudades y aún darles también nuevos príncipes, si constara que esto era conveniente para ellos» (De Indis, $8^{\circ}$ título legítimo. Urdánoz, 724).

33 Cf. Carta al P. Arcos (1534), C.H.P., 5, 138; De Indis, C.H.P., 5, 84; De Iure Belli, C.H.P., 6, 281-285).

34 DEMPF, Alois: La filosofía cristiana del estado en España. Madrid, 1961, p. 88. 
Así pues, del mismo modo que toda sociedad es una armonía entre la singularidad de cada miembro y la totalidad del conjunto, así también lo es la Sociedad Internacional. Ni se diluyen las naciones en un imperio uniforme y totalitario, ni se multiplican los nacionalismos, defensores de intereses particulares en contra del bien común universal.

Las guerras que a lo largo de la historia han ensangrentado el mundo han sido debidas a esta falta de armonía basada en una no comprensión del hombre. Las guerras cesarían, dice Vitoria, por encima de las naciones hubiese, no un Emperador, sino un árbitro, una entidad supranacional, diríamos hoy, que dirimiese los conflictos. Sin duda preludiaba la ONU. Pero es imposible de realizar mientras en el hombre - los estados son dirigidos por hombres particulares- persista el egoísmo y el afán de venganza.

La paz es orden y armonía, en la familia, en el municipio, en la nación, en el orbe entero; juego de derechos y deberes, de dominios: derecho a la libertad y a la educación, derecho a la vida y a la defensa propia y del inocente, derecho a la propiedad privada y a participar de la común, de gobernar la propia nación con independencia buscando su bienestar y de ceder del propio derecho a ello en pro del bien común universal. Esta lección de armonía es la que quieren dar los frescos de la sala «Francisco de Vitoria» del Palacio de las Naciones de Ginebra. Cinco manos unidas en la clave de bóveda y en un lateral: Francisco de Vitoria y sus discípulos de la Escuela tomista de Salamanca.

Vitoria saca las conclusiones de los principios que sienta Sto. Tomás. Pero ambos son deudores del Cristianismo. La fe ilumina la mirada para captar la dignidad del hombre detrás de las apariencias de razas, religión, culturas; enseña universalidad. Allí donde mentes lúcidas, como la de Aristóteles, se oscurecían ante la dignidad de la persona en el esclavo, otros, sin especiales estudios, la descubrían, iluminadas por la fe y el amor, como los santos misioneros. Por eso, me atrevo a decir que la base última de la sociedad internacional está en la teología, «que deja atrás a las demás ciencias que se nutren de lo actual y de las leyes positivas de cada día», ${ }^{35}$ basadas muchas veces en intereses oportunistas, en los cuales está la clave de la no realización del ideal vitoriano.

\section{REALIZACIONES CONCRETAS}

- Primeramente, el surgimiento de la Escuela de Salamanca. Vitoria creó un espíritu nuevo de comprensión y tolerancia internacional que se difundió por España con la colaboración de otros maestros de Teología: Soto, Sotomayor, Medina, Báñez, Suárez, etc., que difundieron por Europa la nueva doctrina. Sobre todo la Escuela creó conciencia entre los intelectuales, la Corona y el pueblo.

-- Un cambio en la Legislación sobre los indios (Leyes Nuevas de 1542, Ordenanzas de 1573...) que, si no pudieron cumplirse del todo por no estar la realidad preparada, fueron abriendo brecha. El ideal debe ir siempre por delante.

- En el comportamiento de misioneros discípulos de Vitoria (Veracruz, Acosta...).

- En la creación progresiva de conciencia universal.

- En el progresivo movimiento de descolonización, que no contradice sino que refuerza el ideal vitoriano que admitía la presencia en las Indias de España como Protectorado hasta que los pueblos estuvieran maduros para autogobernarse. Independencia y cooperación amistosas son perfectamente compatibles, como la historia ha demostrado.

35 Carro, V.: La teología y los teólogos juristas españoles ante la conquista de América». Madrid, C.S.I.C., 1944, 2 vols. Vol 1, pp. 12 ss. 
- La actualidad del pensamiento de Vitoria es patente cuando se coteja con la Doctrina Social de la Iglesia. Ello pone de relieve la fecundidad de la Teología como fuente de ideales realizables.

Ser realizable, no significa serlo aquí y ahora. En tiempos de Vitoria era utopía porque entonces no era posible, ni parece serlo hoy. Toda realización supone lucha, en este caso por la concordia universal, lucha contra el egoísmo y rencor. Es necesario empeñarse en realizarlo porque es realizable, y en la medida en que se realice se ve su efectividad, cosa contraria a lo que ocurriría si se tratara de utopías irrealizables en sí mismas, como lo hemos visto en la historia reciente, cuya puesta en práctica ha demostrado su falsedad intrínseca.

$\mathrm{M}^{\mathrm{a}}$ Lourdes Redondo Redondo e-mail: 1redondore@yahoo.es 